\title{
Synchronized Humanitarian, Military and Commercial Logistics: An Evolving Synergistic Partnership
}

\author{
Pablo Yuste ${ }^{1}$, James Campbell ${ }^{2}$, Deon Canyon ${ }^{2}$, Mark Childers ${ }^{3}$ and Benjamin J. Ryan ${ }^{2,4, *}$ \\ 1 World Food Programme, 00148 Rome, Italy; pablo.yuste@wfp.org \\ 2 Daniel K. Inouye Asia Pacific Center for Security Studies, Honolulu, HI 96815, USA; \\ jrcampbell1948@frontier.com (J.C.); CanyonD@apcss.org (D.C.) \\ 3 Fluor Government Group, Greenville, SC 29607, USA; mark.childers@fluor.com \\ 4 Department of Environmental Science, Baylor University, Waco, TX 76798, USA \\ * Correspondence: benjamin_ryan@baylor.edu
}

Received: 23 May 2019; Accepted: 3 August 2019; Published: 5 October 2019

\begin{abstract}
The increasing complexity and often transboundary scope of complex emergencies are exceeding the capacity of humanitarian logistics systems. The military plays a growing role in supplementing and even leading humanitarian assistance and disaster relief logistics. However, issues relating to military involvement such as sovereignty and cost have refocused the conversation onto capabilities and capacities of commercial logistics providers, who have not been fully engaged and integrated into disaster preparedness, response, and recovery activities. The commercial sector is part of the larger supply chain management system that includes contracting, procurement, storage, and transportation of food, water, medicine, and other supplies, as well as human resources, and necessary machinery and equipment. Military and commercial logistics share many of these elements and tasks daily. The most effective and efficient response combines key elements from humanitarian, military, and commercial logistics systems. Such trilateral cooperation represents the next step in an evolving partnership paradigm that is truly synergistic. We present a Synchronized Disaster Relief Model, as well as multiple examples of how military, commercial, and humanitarian supply chains each bring unique capabilities to disaster relief operations, and how these three supply chains can complement each other in a synergistic manner, through synchronized action.
\end{abstract}

Keywords: supply chain management; synchronized; synergistic; inclusiveness; interoperability; complex emergencies

\section{Introduction}

Due to the increasing complexity, and often transboundary nature of disasters and complex emergencies, the capacity of the humanitarian logistics system is stretched beyond its ability to cope $[1,2]$. To overcome this challenge, the military is increasingly being called on to supplement, or even lead, humanitarian assistance and disaster relief (HADR) logistics across the Indo-Pacific. This trend continues due to a combination of increasing frequency and intensity of disasters, and aid funding not meeting demand [3]. However, the latent and powerful capabilities and capacities of the commercial logistics system have not been fully engaged and integrated into disaster preparedness, response, and recovery activities. This commentary proposes a Synchronized Disaster Preparedness and Response Model that integrates the resources and supply chain management systems of military, commercial, and humanitarian disaster response activities. The rationale for the proposed model is based on examples of disaster responses included throughout the text that includes humanitarian, military, and commercial actors working concurrently but not in a synchronized manner, and which 
clearly would have been more effective if enhanced coordination between the three has been pre-planned and implemented. This paper is intended to provide an inclusive intellectual framework for stimulating ingenuity, invention and creativity, and stimulate discussion on more effective strategies for managing the novelty of large-scale natural and manmade disasters.

Humanitarian logistics embeds into local, national, and international disaster management systems. It is part of the larger supply chain management system that includes contracting, procurement, storage, and transportation of food, water, medicine, and other supplies, as well as human resources, and necessary machinery and equipment. This includes the process of planning, implementing, and controlling the efficient, cost-effective flow and storage of goods and materials as well as related information, from point of origin to point of consumption, to save lives and alleviate suffering for beneficiaries [4]. Military and commercial logistics share many of these same elements; however, humanitarian aspects place additional emphasis on saving lives and ameliorating suffering, before and after disasters have struck.

When a natural or human-made hazard results in massive damage or loss of life that exceeds a country's capacity to cope, it becomes a disaster and international assistance is recommended. Although all disasters are local in their impact, HADR activities are global in their scope, because in a globalized economy the ramifications of major disasters are international. When natural disasters intersect with zones of conflict, complex human emergencies are often the result. In such emergencies, the critical need for all available relief resources is manifest and the three sectors are drawn together, often with little pre-planning or coordinated response.

Humanitarian, military, and commercial logistics must be coordinated and synchronized before, during, and after disasters. "Coordination" by itself is actually a second-order output; the results of such coordination are what matters. It can be challenging to assess the extent to which coordination activities contribute to final outcomes, which is why we recommend rigorous monitoring and evaluation through all phases of a synchronized disaster response. This disaster life cycle approach is required because natural disasters are increasing worldwide in frequency, severity, and complexity due to a combination of a changing climate, globalized markets, and rapid urbanization in flood plains and storm-prone coastal zones [5-7]. The global humanitarian system is struggling to meet the demand imposed by disasters along with increasing complex emergencies and populations of internal migration and international refugees [8,9]. A key challenge for the system is exemplified by the $44 \%$ gap in 2018 between the funding required by aid agencies and what was provided, higher than the $28 \%$ gap in 2009 , and $39 \%$ in 2014 [3]. A multiplier effect on these challenges is that delivery of humanitarian aid is also becoming more complex and is increasingly plagued with low volunteer skills and high personnel turnover [2].

In natural catastrophic disasters, military logistics systems are often engaged because their proficiencies in heavy-lift transportation, communications, and security are hard to match. Additionally, commercial donors with limited resources may defer to military logistics support in HADR rather than providing resources themselves to small non-government organizations (NGOs), because of the much greater capacity of the military, and because military assistance is generally free to the beneficiaries and to the impacted countries. However, this reality does not reflect the true cost of the military and risks the creation of unhelpful "competition" between military and humanitarian actors. This makes the interaction between military and donors challenging, as the military are funded via appropriations by their respective governments. Military collaboration can involve domestic or international militaries and can take several forms (Table 1). 
Table 1. Civilian-military collaboration on disaster logistics.

\begin{tabular}{|c|c|c|c|}
\hline & & & Civilian \\
\hline & & Domestic & International \\
\hline Military & $\begin{array}{c}\text { Domestic } \\
\text { International }\end{array}$ & $\begin{array}{l}\text { Internal civil-military relations } \\
\text { Traditional military focus }\end{array}$ & $\begin{array}{l}\text { Traditional focus of humanitarian actors } \\
\text { International relations or "UN-CMCoord" }\end{array}$ \\
\hline
\end{tabular}

Military logistics support is typically intense and immediate, highly mission-focused, and of relatively short duration. However, the high quality and seemingly limitless quantity of military support conflicts with the development and use of local capacity and the consequent disruption of local supply chains can even drive potential local suppliers of relief commodities and services permanently out of business. Subsequently, there is a risk that when the military departs the site of the disaster following mission accomplishment there could be an unintended vacuum in the supply of critical goods and services, which could have long-term negative consequences. As humanitarianism is guided by the concept of "Do no harm", maximum beneficence must always be tempered with principled realism.

Despite the highly effective and beneficial short-term impact military actors may have on the ground, there are challenges related to cost, adequacy, and competition for the aid pipeline, as well as lack of understanding between the military and humanitarian actors. An overview of these challenges created by this type of deployment is shown as follows.

- Cost: Military logistics is highly effective, but it is the least desirable choice in terms of cost-effectiveness (efficiency) and its impact is thus reduced when cost is taken into consideration. Military assets are thus typically requested during the first phase of response operations when rapid deployment and effectiveness are considered more important than cost efficiency.

- Adequacy: Military logistics is highly specialized. Often, the cargo for military operations is precisely adapted to military assets with a high level of standardization. For instance, military vehicles fit in military planes. With the exception of non-food items and tents, humanitarian organizations have not gone through this standardization process for all their assets; meanwhile, the commercial sector on a daily basis is required to maintain a system that can be easily integrated into existing distribution networks, otherwise their business would fail.

- Competition for the pipeline: Military assets are heavy and require a big part of the existing pipeline for operating. Military staff have complex protocols for deployment that include a minimum operational equipment kit that is usually heavy. The deployment of what the troops need themselves for their own sustainment might overload the existing logistics capacity in the area. Likewise, the same pipeline must be used when the military withdraws. A good example of this situation took place during the Haiti earthquake. Usually, the deployment of military assets is coordinated with the authorities separately from the overall coordination with the humanitarian community. This creates issues regarding the prioritization of aid.

- Lack of understanding between military and humanitarian actors: Regardless of all the good intentions, military, and humanitarian are two very different working cultures, with fundamentally disparate primary missions. Promoting a better understanding and building trust is still a lesson to be learned by both parties.

Commercial logistics systems are fundamentally driven by profit and are designed to align producers with customers. However, increasing natural disasters in the Indo-Pacific region and the existence of a complex network of globalized supply systems means that traditional forecast-driven demand and predictability models must incorporate more reactive, event-driven response strategies. The humanitarian sector has long relied on agile supply chain management (SCM), due to high uncertainty, limited budgets, and increasing pressure on cost efficiency $[10,11]$. Corporate Social Responsibility (CSR) is an important factor that motivates commercial organizations to offer disaster assistance to impacted areas [12]. Assistance can take the form of cash donations, material resources, volunteering, delegation of personnel, specialized expertise, and distribution infrastructure. 
Given that humanitarian, military, and commercial logistics systems each have distinct capacities, resources and skills, the most effective and efficient disaster response should incorporate key elements that focus on unique core capacities from each of these three sectors. Governments are most likely to avoid making errors of commission, as these can be seen as mistakes and not as a result of funding shortages. The military, on the other hand, seeks to avoid errors of omission, as military leaders are charged with taking initiative and risks to meet the mission. Humanitarian organizations and commercial entities have incentive to avoid errors of commission leading to quantifiable loss of lives and loss of profit, and errors of omission resulting in loss of donor support and loss of profit opportunities, respectively. Synchronized response efforts complement and balance each other's core capacities in this regard and represent an evolving partnership paradigm that is truly synergistic, in which the combined response is more powerful than the sum of the individual contributions. This paper explores how this can be achieved by describing the legal frameworks guiding HADR, humanitarian principles, SCM systems, consequentialist versus deontological philosophies, prepositioning versus postponement, and synergistic disaster relief.

\section{Legal Frameworks}

The two documents that guide the use of Military and Civil Defense Assets (MCDA) in emergencies are the Oslo Guidelines on the use of Foreign Military and Civil Defense Assets in Disaster Relief for a natural disaster and the Guidelines On The Use of Military and Civil Defense Assets to Support United Nations Humanitarian Activities in Complex Emergencies (MCDA) [13,14]. A complex emergency, as defined by the Inter-Agency Standing Committee (IASC), is "a humanitarian crisis in a country, region, or society where there is a total or considerable breakdown of authority resulting from internal or external conflict and which requires an international response that goes beyond the mandate or capacity of any single agency and/or the ongoing United Nations (UN) country programme" [15]. The provision of the guidelines for complex emergencies is much stricter because neutrality of the forces can become more easily compromised.

During an emergency response, it is vital to understand that the main objective of military forces is achieving their mission. In natural disasters, the military mission is to carry out HADR activities that are beyond the capacity of existing humanitarian and civil providers; therefore, no conflict of interest exists between military and humanitarian providers. However, in complex emergencies, ensuring a safe secure environment may take precedence over providing relief operations. Thus, the association of aid with military forces may inadvertently put civilian humanitarians and their beneficiaries at operational or even personal risk.

In complex emergencies where dynamic operations are taking place, military HADR activities may be more restricted. To ensure impartiality of forces and their availability to support humanitarian operations, the military must adhere to the following standards and activities:

- Direct assistance: Face-to-face assistance of good and services should never take place in complex emergencies [15]. This provides protection for beneficiaries by preventing approaches to the military during dynamic operations and protects humanitarian actors by ensuring they are not confused with the military.

- Indirect assistance: One step removed from the population is acceptable, but always under the principle of last resort [15].

- Infrastructure support: This is acceptable and is the provision of general services that facilitate relief, but not necessarily visible or intended solely for the benefit of the affected population, such as port or airport rehabilitations [15]. For example, the use of U.S. air controllers at the airport in the aftermath of Haiti's earthquake in 2010 [16].

- Security: The primary role of the forces must be providing security for an unimpeded humanitarian access to all the organizations. The security should be area security, avoiding to the extent possible the use of direct escorts. However, in terms of logistics, any support will follow the following 
principles in line with the MCDA support in disasters and complex emergencies summarized by the Inter Agency Standing Committee:

1. Humanity, neutrality, and impartiality

2. Humanitarian access to vulnerable populations as a main driver for the cooperation

3. Perception of humanitarian action, so there are not misperceptions leading to compromise of the neutrality

4. Needs-based assistance free of discrimination

5. Civilian-military distinction in humanitarian action

6. Operational independency of the humanitarian actors

7. Security of humanitarian actors

8. Do no harm

9. Respect to the international legal instruments

10. Respect for culture and customs

11. Consent of parties to the conflict

12. Option of last resort. Use of military assets, armed escorts, joint humanitarian military operations, and any other actions involving visible interaction with the military must be the option of last resort.

13. Avoid reliance on the military [13].

However, these principles are often tempered by reality. In 2015, 150 health facilities were bombed and over 220 systematically targeted attacks were launched on separate medical facilities in Syria [17]. This contravenes any "law of war" protections in the $21^{\text {st }}$ century. The World Humanitarian Summit in Istanbul, 2016 fails to address international humanitarian law and civilian protection despite the summit's orientation towards organizations engages in humanitarian assistance [18]. This lack of consideration of legal and physical protection neglects the intellectual contributions of the security sector, which is invariably called upon for assistance when civil and humanitarian agencies are overcome. As stated in Canyon and Burkle (2016), "Clearly, today's wars are pursued on the same barbaric belief last seen centuries ago: the more egregiously and violent the war is waged the shorter it will be".

\section{Humanitarian Principles}

Humanitarian activities undertaken in HADR are founded on four key principles [19]:

- Humanity-Human suffering must be addressed wherever it is found. The purpose of humanitarian action is to protect life and health and ensure respect for human beings.

- Neutrality-Humanitarian actors must not take sides in hostilities or engage in controversies of a political, racial, religious, or ideological nature.

- Impartiality-Humanitarian action must be carried out based on need alone, giving priority to the most urgent cases of distress and making no distinctions based on nationality, race, gender, religious belief, class, or political opinions.

- Independence-Humanitarian action must be autonomous from the political, economic, military, or other objectives that any actor may hold about areas where humanitarian action is being implemented.

Adherence to the humanitarian principles can be challenging, particularly in complex human emergencies where a natural disaster occurs in a zone of conflict. Reconciling the different prioritizations of these principles by humanitarian, military, and commercial actors, and leveraging the unique strengths of their respective supply chains to achieve a common goal represent persistent challenges in disaster logistics operations. Table 2 demonstrates the limitations of military logistical support in different categories of humanitarian assistance operations. In this table, the different HADR scenarios 
have been categorized as: rule of law where civilian and military authorities exert an overall control of the area and are perceived as legitimate by the population; low intensity conflict relates to the population perceiving the legal authorities as legitimate, some groups keep political grievances that undermine the neutrality of the forces; high intensity conflict is when legal authorities are often challenged by low intensity warfare actions such as sabotage and terrorist activities from groups holding political grievances while authorities keep an overall control on the territory; and kinetic operations is where two or more parties dispute control of the territory through active warfare including the use of lethal force. Across this spectrum the need for security support for HADR increases.

Table 2. Humanitarian assistance and disaster relief (HADR) logistical support from the military.

\begin{tabular}{|c|c|c|c|c|c|}
\hline & \multicolumn{5}{|c|}{ Military impartiality and HADR availability decreases } \\
\hline \multirow{4}{*}{ 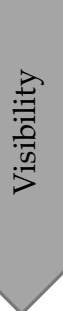 } & Humanitarian Role & Rule of Law & $\begin{array}{l}\text { Low Intensity } \\
\text { Conflict }\end{array}$ & $\begin{array}{l}\text { High Intensity } \\
\text { Conflict }\end{array}$ & $\begin{array}{l}\text { Kinetic } \\
\text { Operations }\end{array}$ \\
\hline & Support services & Provided & Provided & Some & Some \\
\hline & Indirectly supporting & Provided & Some & Some & Nil \\
\hline & Directly supporting & Some & Nil & Nil & Nil \\
\hline
\end{tabular}

However, the $\mathrm{UN}$ is often obliged to maintain a delicate and dynamic balance between the humanitarian imperative of saving lives and alleviating human suffering, and the four core humanitarian principles, particularly impartiality. This dilemma forces UN humanitarian agencies to keep a constant access negotiation that is far from easy and creates an ethical challenge. This "humanitarian bargain" has resulted in the erosion of UN legitimacy. Some authors consider that the humanitarian system "faces a crisis of legitimacy, capacity and means, blocked by significant and enduring flaws that prevent it from being effective" [20]. In flagrant disregard for the first goal of the 2016 World Humanitarian Summit to "Reaffirm our commitment to humanity and humanitarian principles" and the second core responsibility- to "uphold the norms that safeguard humanity", UN Security Council resolutions have repeatedly sanctioned government interference in the delivery of food and medical aid that has resulted in civilian deaths and starvation [21]. Following this, a report reveals that the UN abdicated control of aid delivery to the Assad government in Syria, which betrayed the humanitarian principles of impartiality, independence, and neutrality and directly resulted in the prevention of aid to those most in need [22]. Thus, the humanitarian principles are eroding and any evolution in supply logistics management for disasters needs to be efficient, effective, and rededicated to compliance with these principles.

\section{Consequentialist Versus Deontological Philosophies}

While offering maximum beneficence to the greatest number of victims of a natural disaster is a common goal shared by all relief providers, there are two competing philosophies that define ethical behavior and "rightness" in relief efforts. The consequentialist philosophy holds that "the ends justify the means". If the objective of providing the maximum relief is met, any and all actions necessary to achieve that objective are ethical and right [23]. In contrast, the deontological philosophy argues that if all current laws, regulations, and procedures are strictly followed, whatever outcome achieved by the operation is ethical and right [24]. The goal-oriented consequentialist approach focuses on effectiveness and emphasizes "doing the right thing". However, a risk is that laws may be broken, and some human rights are abrogated. Corruption and moral hazard also potentially loom large in 
the shadows of consequentialism. The deontological approach focuses on efficiency, and emphasizes "doing things right", but it may unnecessarily prolong suffering. Several authors have addressed this "new humanitarianism" and have argued for increased professionalism among humanitarians and non-governmental HADR organizations $[25,26]$. The complexity of disaster logistics operations involves both philosophies, interwoven as practicable throughout the SCM system, and most challenges can be mitigated by a well-designed monitoring and evaluation plan.

\section{Supply Chain Management and the Commercial Sector}

An important focus for enhancing synergy is SCM, which involves the same basic elements of whether the organization providing logistical support is humanitarian, military, or commercial. First, managers must work with the impacted country's government to identify the objective of the mission, which defines the requirements. Then appropriate goods, services, personnel, equipment, and machinery must be sourced, which involves contracting and procurement. At this point, the core logistics elements are assigned and implemented including transportation, storage, and delivery to end users. In addition, an SCM system must maintain a disciplined and accurate monitoring and evaluation process to ensure that mission objectives are met effectively and efficiently. Limited synchronization between the logistics systems of the three sectors inevitably results in a lack of standardization and inability to evaluate the success of joint operations.

The commercial sector includes enterprises, companies, businesses, industry, private academia, and research institutions with profit orientations. Additionally, $85 \%$ of investments across the world are from the private sector and the majority of infrastructure and networks owned/operated by the commercial sector [1]. Supply chains increasingly are complex and global, so a disaster in Thailand can be disruptive to businesses as far away as Nebraska or Germany. For example, damage to Renesas microchip maker in Japan after the 2011 earthquake led to 150,000 fewer Toyotas being produced in the U.S. Honda factories in Malaysia, North America, and Japan stopped production after Thailand floods in 2011, due to supply interruptions (USD1.4 billion losses), and as Thailand produced 43 percent of the world's hard disk drives, the 2011 flood caused a 77\% drop in production and temporary tripling of prices [27].

\section{Prepositioning versus Postponement}

The provision of relief supplies involves two complementary frameworks for SCM: prepositioning and postponement. The most widely subscribed framework is prepositioning [28,29]. This is where relief supplies are stored continuously as far forward as possible, in areas prone to natural disasters such as massive seasonal flooding, predictable cyclone events, risk of earthquake, and associated geophysical effects or tsunamis. The World Food Programme (WFP) has prepositioned strategic disaster relief stocks at six United Nations Humanitarian Response Depots (UNHRDs), in a global network sited in Ghana, UAE, Malaysia, Panama, Italy, and Spain (Figure 1). 


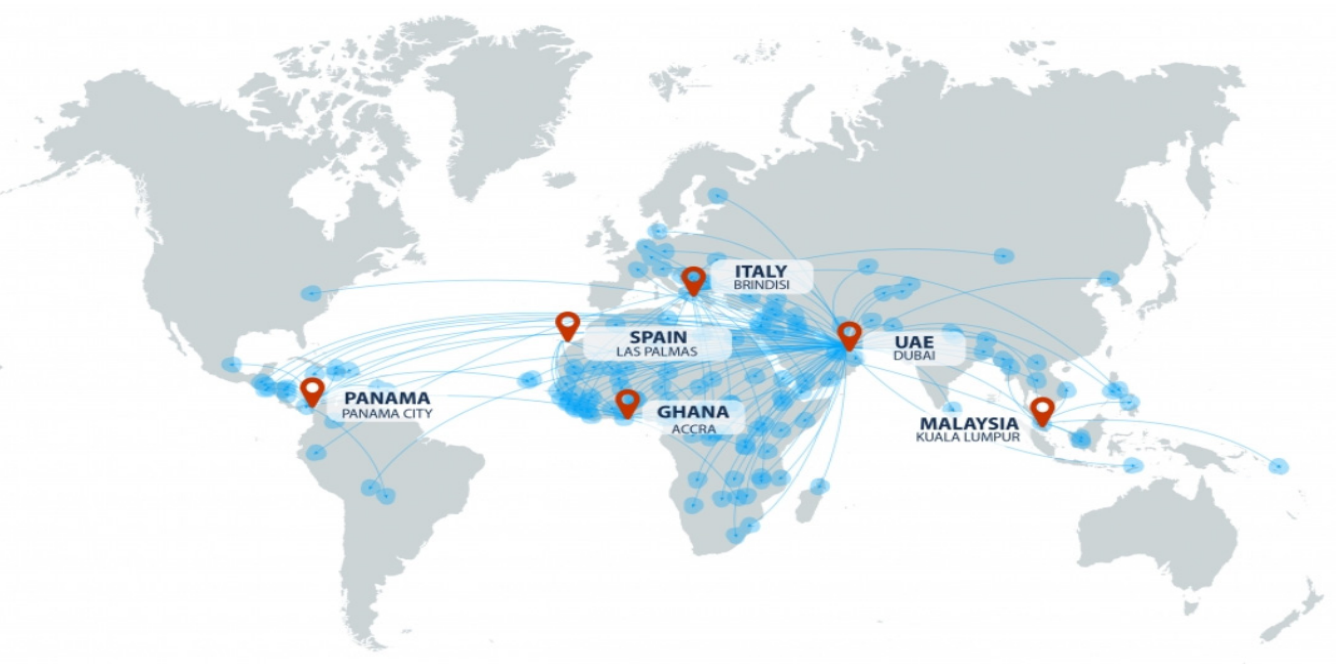

Figure 1. United Nations Humanitarian Response Depots [30].

The UNHRD is a network of strategically located hubs for prepositioned relief items and humanitarian support equipment [31]. The hubs, also knowns as depots, are large warehouses managed by the WFP and are located at key road, rail, air, and sea transportation hubs that allow relief items to be delivered intra-regionally within 24 to $48 \mathrm{~h}$ [30]. The WFP is the United Nation's chief agency for mitigating world hunger, and it manages a complex global supply chain that controls the availability, accessibility, and use of global food supplies due to disasters.

The humanitarian response depots (warehouses) contain emergency relief goods such as medical kits, shelter items, ready-to-use food, IT equipment, and operational support assets that are customized to support emergency preparedness and response [31]. The depots have been used to provide relief items after disasters and during complex emergencies. In 2018, for example, this included support to responses in Bangladesh (refugee crisis), Democratic Republic of Congo (cholera outbreak), Indonesia (earthquake and tsunami), Papua New Guinea (earthquake), and Yemen (complex emergency) [32]. This model has been followed by the International Federation of the Red Cross (IFRC), which has achieved significant efficiencies in disaster response through the use of its network of Regional Logistics Units [33] and the Association for South East Asian Nations (ASEAN) Coordination Centre for Humanitarian Assistance (AHA) through the Disaster Emergency Logistics System for ASEAN.

Prepositioning of relief goods presents challenges. Unused supplies expire and must be replaced, which adds to costs, as does the requirement for constant security to preclude diversion of supplies away from aid recipients and reduce potential for violence [10]. Being in high-risk areas, the satellite stockpiles of relief supplies can themselves be damaged or destroyed by disaster events. Importantly, every disaster is unique in terms of relief requirements, making it difficult to stock resources appropriate for all possible disaster scenarios. While prepositioning can be effective in supporting a more rapid response, it can also result in simply giving beneficiaries what is available, rather than what they may actually need.

Postponement differs from prepositioning in that supplies are held back, in generic form, as strategic inventory at centralized logistics hubs, from which they are distributed following a rapid needs assessment from the site of the disaster. While this may cause some delay in distribution of supplies, the relief will be more efficient because the impacted populations will receive more precisely what they need. Supplies that are unnecessary or unsuitable causes bottlenecks and monopolize valuable transportation assets, storage space, and personnel. This is because they must be delivered into the disaster site via the impacted country's SCM system, and then carried back out if unused by the same system. For example, in Sri Lanka, two weeks after the 2004 tsunami authorities requested no more pharmaceuticals; however, they continued to arrive, resulting in approximately 150 metric tons (130 truckloads) of unusable medications being destroyed. Only $10 \%$ of drugs donated were on the 
Ministry of Health expressed list of medications, which was issued two days after the disaster [34]. Additionally, aid to Nepal began arriving a few hours after the first earthquake (2005), and continued for days, flooding the single international airport in Kathmandu to the point of standstill [35].

Optimizing SCM in a disaster relief operation will involve both prepositioning and postponement. While critical medical supplies for life-saving trauma treatment and for infectious disease control, as well as for chronic non-communicable disease support, are certainly justified and should be prepositioned, the reality is that resources such as shelter materials and some foodstuffs often can be postponed briefly until accurate estimates of the types and quantities that are actually required can be ascertained. Postponement can involve the actual manufacturing of recipient-specific, validated relief supplies, just-in-time shipping models, assembly of palletized relief "kits", or shipping and storage strategies based on accessibility, weather, and verified transportation infrastructure status in the impacted areas. The humanitarian principles demand that aid be provided impartially, based on the greatest need. To realize the maximum beneficence, logisticians must operate scientifically and systematically, not emotionally.

One approach to optimizing disaster logistics in SCM combines prepositioning and postponement. This model divides the supply chain geographically into two spatial components, beginning at warehouses in the major transportation hubs and ending with humanitarian supplies being delivered into the hands of the impacted beneficiaries. The large warehouses will contain components-basically raw materials for finished aid products and targeted relief kits. In the event of a disaster, prepositioned supplies needed immediately to save lives and reduce suffering are rushed to the site of the disaster, and a rapid needs assessment is concurrently conducted. The assessment is delivered back to central supply chain managers, who quickly assign requirements and source the supplies from appropriate warehouses at the supply hubs. The components then begin transport toward the disaster site, stopping at secondary hubs for assembly into precisely defined kits for onward delivery to the point of need.

Packing, shipping, assembling, and storage of relief products can be the costliest elements in a supply chain [36]. Efficiencies are gained from minimizing repacking of supplies once deployed. Christopher and Towill [37] discuss the "decoupling point" in the SCM where upstream "push" from suppliers meets downstream "pull" from beneficiaries. They conclude that strategic inventory should be maintained in generic form as far downstream as possible, and that demand information from beneficiaries should move as far upstream as possible. Proper positioning of the decoupling point for materiel and information flows can produce a hybrid supply chain that combines a lean and efficient supply upstream and an agile and effective supply downstream.

\section{The Goal: Synchronized Disaster Relief}

A conceptual framework for how a synchronized disaster relief system would work is provided in Figure 2. Within this framework, commercial supplies and logistics need to be better integrated into the supply chain management for disaster relief. This supply chain includes military logistics, national disaster management agencies and humanitarian logistics. When commercial elements are also integrated, work can commence on achieving synchronized disaster relief. Within the disaster relief spectrum, the current system is constrained at the communication level, as there is little to no deconfliction of capacity and capability between the commercial, military, national disaster management and humanitarian sectors. However, if one excludes the commercial sector, the level of disaster relief synchronization across the spectrum would be currently between cooperation and agreements, and coordination of preparedness and response. Joint disaster relief training needs to invest more in preparedness to respond and preparedness to recover, rather than just focusing on the actual response phase of the operation. For example, there is a standby arrangement for assets and capacities by ASEAN member states along with Standard Operating Procedure for Regional Standby Arrangements and Coordination of Joint Disaster Relief and Emergency Response Operations. In addition, the AHA Centre coordinates with National Disaster Management Organizations (NDMOs) of the ASEAN member states to distribute those relief goods to disaster-affected countries as needed 
to support emergency response efforts [38]. Pre-agreed commitments by regional governments to respond with specific actions and specific resources represent a rapid evolution in recent years, and by integrating the private sector in a similar manner, the provision of disaster relief to beneficiaries will be maximized.
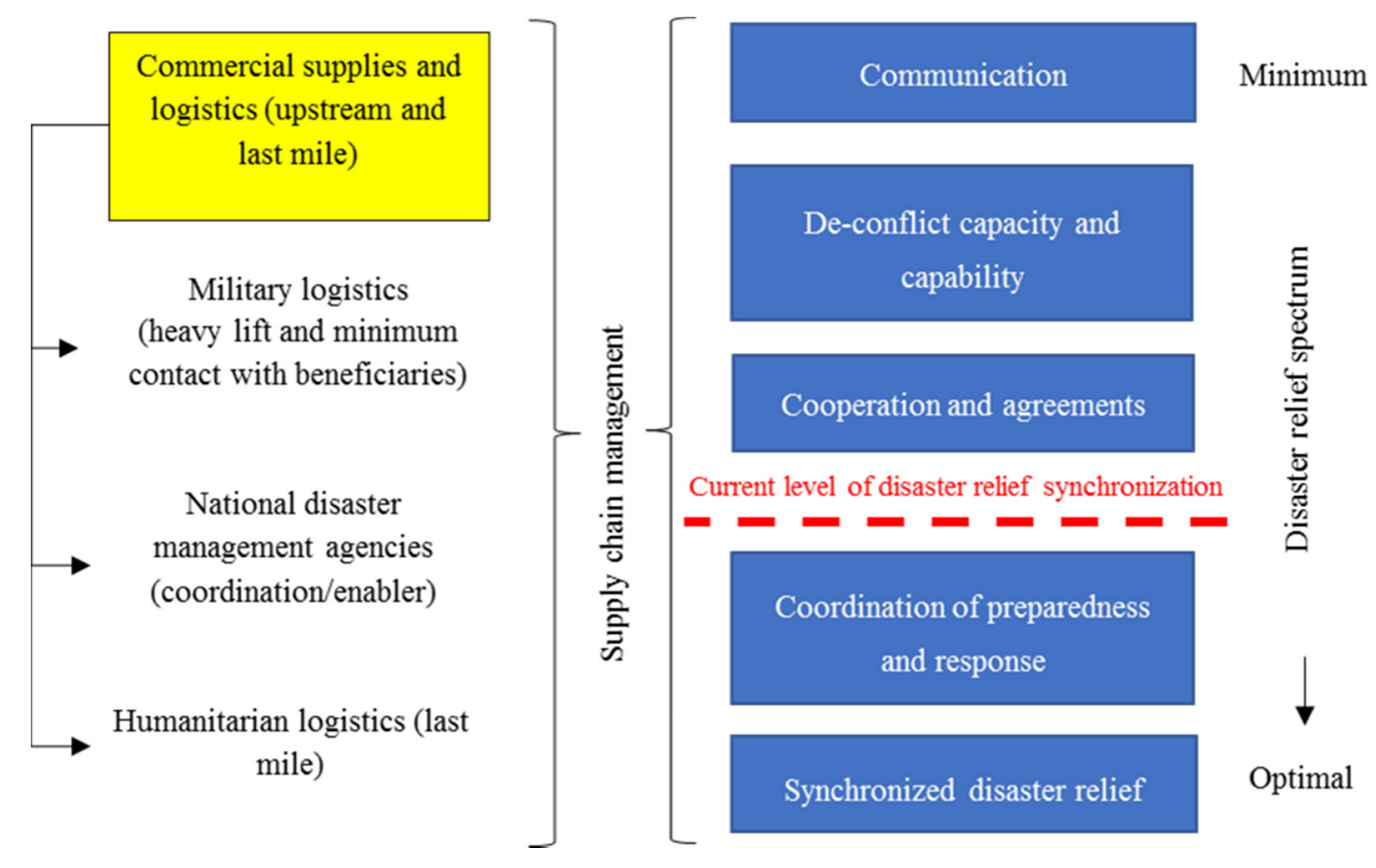

Figure 2. Conceptual framework for synchronized disaster relief.

A key aspect for achieving a synergistic logistics system is to preclude military, commercial, national disaster management, and humanitarian systems from competing for the same resources. To prevent this from occurring the commercial sector should focus on upstream provision of goods and services (sourcing and providing such as food from farmers) along with the last mile, which is the delivery to beneficiary (for example, sale/distribution of food from existing businesses). The military should use its strength, which is heavy lift of goods and services from point A to point B and speed (predeployed forces may also conduct rapid needs assessments). Focusing the military on this specific role can maximize the speed of relief if integrated into last mile activities for commercial and humanitarian logistics. National disaster management agencies should coordinate and enable the delivery of relief through the supply chain management system, providing continuous updates to all participants along the entire supply chain. The contact of the aid delivery should be led by the commercial sector with support provided as required by the local government and humanitarian sector. Achieving this would be a paradigm shift from "immediate response" activities to "productive initiatives" across the disaster cycle.

This synergistic approach is urgently required, particularly in complex emergencies. Military support for logistics post-natural disaster can be politically controversial, so maintaining a low profile is important. Moreover, there are arguments that the provision of any humanitarian assistance in conflict settings can prolong conflict $[39,40]$.

There are many examples that demonstrate the need and the benefit of a synchronized approach in coordinating material and logistics in both international and domestic recovery missions. Due to the evolving nature of HADR missions and the urgency of material and equipment needs, initial coordination for material between the military and different commercial entities can be challenging. There should be one party responsible for near-term material acquisition and another for long-term supplies. Often, both military and commercial organizations have responsibility for near-term and long-term material supply. A consequence of both parties competing for 
similar resources are compatibility issues such as electrical, heating, ventilation, air conditioning, and plumbing. Additionally, the military and commercial organizations risk duplicating the same supplies. An approach that is proven to help resolve this situation includes the government and contractor establishing daily and weekly coordination meetings for construction and logistics. This ensures the availability, compatibility, and deconfliction of resources, as well as coordination of both immediate and longer lead time vendors, to meet recovery milestones.

An important factor in building a model or system for military, commercial, and humanitarian logistics synergy is recognizing their different goals and motivations. For instance, the commercial sector will not have the same political inclinations imposed by the government deploying Military and Civil Defense Assets (MCDA). There needs to be a focus on finding areas of common cooperation, where military and humanitarians can find synergies under their own mandate. Cooperation during evolving emergencies can help balance reliance on military assets and move to a more humanitarian and commercially oriented operation.

In most cases, commercial entities can provide cheaper services than government or military and their professional services should be on the front line. Local humanitarian and commercial assets are the first assets brought to bear in a disaster. After one to three days, MCDAs will be integrated in the response, and international humanitarian and commercial assets take longer to deploy. Local assets and human resources will likely be directly affected by the crisis, require time to reorganize and start operating again, or may not be willing to take the commercial risk in the early stages. Thus, pre-crisis memorandum of understanding agreements with local commerce are vital to ensuring a rapid and committed response. During the first moments of the crisis, saving lives becomes the most important goal, regardless of the cost. In later stages of the response, focus will shift to prioritizing cost-effective measures. As the response evolves, more humanitarian and commercial actors will be available. The supply lines stabilize and the use of MCDAs can be reduced for more neutral and cost-effective solutions.

Frequently, local and external responses put pressure on an already stressed local vendor base. An alternative approach requires military and commercial coordination of resources and is based on a planning in depth approach that is very similar to the military planning system. At any given time, three levels of military planning are concurrently being performed: present operations, future operations, and future plans. By implementing a similar approach to HADR logistics, each sector could pre-identify which resources they need and when they need them.

\section{Case Study: Synchronized Disaster Response in Humanitarian Emergencies}

To implement a synchronized system, a system-wide change is required. This includes all stakeholders involved in HADR such as governments, U.N. agencies, humanitarian organizations, and the military that demonstrate a willingness to work cooperatively with the commercial logistics sector [1]. To achieve this, the commercial sector through industry bodies should be invited and encouraged by governments, NGOs, international organizations, the military, and U.N. agencies to participate in all aspects of preparedness, response, and recovery (including reconstruction). This will ensure sustainable progress is made towards a synchronized logistics system by maximizing inclusiveness, efficiency, and effectiveness. In the Asia-Pacific region, for example, the major inter-governmental business development organization is the Asia Pacific Economic Cooperation (APEC) [41]. APEC encourages the commercial sector to engage in disaster preparedness and response, to reduce the threat of disruptions to business and trade and enhance economic growth and prosperity in the Asia-Pacific Region.

A recurring major challenge in international aid response to natural disaster involves domestic airports in impacted countries becoming overwhelmed by the tempo and sheer volume of relief operations. Following the Haiti earthquake in 2010, the Port Au Prince airport suffered near operational collapse as huge numbers of flights converged within the first few days, delivering a wide variety of needed and often un-needed relief supplies. Air traffic controllers from the U.S. military were sent to 
Port $\mathrm{Au}$ Prince to help organize and deconflict air deliveries at the Toussaint L'ouverture International Airport [42]. Simultaneously, a civilian Disaster Response Team (DRT) from Deutsche Post DHL Group [43] arrived to assist with airport warehousing and distribution activities. The combined specialized skills of the military and commercial agencies kept supplies flowing and maintained air and ground safety; however, as this cooperation between the military and the private sector was on an ad hoc basis, lack of established joint metrics prevented measuring performance.

A range of challenges with airborne relief were also experienced globally following humanitarian emergencies in 2018. For example, $45 \%$ of all relief supplies to the Democratic Republic of Congo arrived by air, whereas in Indonesia only $10 \%$ were air shipped. Regarding type of cargo, $41 \%$ of the total to Yemen was logistics supplies (tents, vehicles, and generators), but only $15 \%$ of total relief supplies to Indonesia were of this category [33]. These variations reflect the dynamic nature of disasters and the unpredictable requirements of subsequent aid responses by air, sea, and land. Synchronization of military, humanitarian, and commercial aid responses through joint planning and preparedness training, with established performance metrics, will greatly increase efficiency and effectiveness, while validating the Synchronized Disaster Response Model. In comprehensive disaster management, greater investment in preparing to respond and preparing to recover, rather than on just the actual response phase itself is critical. It is recommended that a national framework focused on a whole-of-society approach be developed for planning and training, to include desktop and field exercises. This synchronized preparation will catalyze a new generation of leaders who are more capable of dealing with novelty and maintaining situational awareness in disaster response.

The ASEAN is currently organizing the ASEAN Militaries Ready Group (AMRG) on HADR to become operational in 2019. The AMRG enables disaster-impacted countries in the region to request support of disaster response specialists from the militaries of ASEAN member states. The AMRG is designed to integrate into existing disaster response mechanisms and adhere to established HADR best practices to save lives. Following the devastating Indian Ocean tsunami of 2004, a series of Asia-Pacific Conferences on Military Assistance to Disaster Relief Operations took place, leading in 2014 to the formation of the Regional Consultative Group (RCG) on Humanitarian Civil-Military Coordination for Asia and the Pacific [44]. The RCG was achieved through sustained dialogue between the parties, interspersed by scheduled formal meetings. These and other collaborative civilian-military endeavors in the region are helping to synchronize international disaster response in a synergistic way to produce superior outcomes. This very positive trend in collaborative disaster response will be further strengthened by the integration of commercial disaster response entities and resources in a truly holistic model, leveraging the power of the military, government civilian, commercial, and humanitarian logistics systems.

\section{Conclusions}

The most effective and efficient disaster relief model would combine key elements from humanitarian, military, and commercial logistics systems. Achieving this is vital to save lives and alleviate suffering for those who are impacted by disasters and complex emergencies yet are currently underserved by existing approaches. Complex emergencies benefit from military participation due to the deteriorated security situation, and commercial and humanitarian actors are increasingly obliged to cooperate with these military relief missions. The political uncertainty of complex emergencies also creates "signal noise" that makes it more difficult for individuals, firms, and communities to assess requirements correctly and consequently undermines their ability to form accurate expectations. Therefore, an inclusive, synchronized planning and execution strategy helps mitigate operational gaps. Joint planning and combined operations also present valuable learning opportunities for the different agencies to observe best practices and incorporate lessons learned into their own supply chains.

Key findings from this work include: (1) military, commercial, and humanitarian sectors each bring unique core capacities and resources, and their synchronized response is more synergistic than the sum of the individual contributions; (2) humanitarian, military, and commercial logistics must 
be coordinated and integrated before, during, and after disasters to avoid unhelpful "competition" between actors; and (3) joint disaster relief training needs to invest more in preparedness to respond and preparedness to recover, rather than just focusing on the actual response phase of the operation. The Synchronized Disaster Relief Model proposed in this commentary is intended to provide a comprehensive intellectual framework for stimulating ingenuity, invention, and creativity. This paper should be viewed as a starting point for discussion to inform Memoranda of Agreement, leading to the creation of future standard operating procedures for managing the novelty of large scale natural and manmade disasters. Enhanced inclusion of the commercial sector in a whole-of society approach will provide clarity on how and when logistics capacities and capabilities are best mobilized at the time of a disaster [45] and stimulate discussion on more effective disaster relief strategies. Based on these new strategies, future research should focus on rigorous operational field studies and hypothesis testing incorporating robust monitoring and evaluation plans. Quantitative data from such studies will help deconflict and synchronize humanitarian, military, and commercial agencies' supply chain management procedures, highlight logistics bottlenecks, and mitigate negative impacts of disasters and complex emergencies on lives and livelihoods.

Author Contributions: Unique authors' contributions: P.Y.-humanitarian logistics perspective; M.C. —commercial logistics perspective; J.C., B.J.R., D.C.—government/military logistics perspectives.

Funding: This research received no external funding.

Conflicts of Interest: All authors declare there is no conflict of interest. The views expressed in this article are those of the authors and do not necessarily reflect the official policy or position of the Daniel K. Inouye Asia-Pacific Center for Security Studies, the Department of Defense, or the U.S. Government.

\section{References}

1. Ryan, B.; Canyon, D.; Burkle, F.; Campbell, J.; Bhatia, S.; Li, W.-S.; Chen, K.-H. Rationale for Involving the Private Sector in Humanitarian Assistance and Disaster Relief in the Indo-Pacific; National Science and Technology Center for Disaster Reduction Bulletin: New Taipei City, Taiwan, 2018; Volume 160.

2. Richardson, D.; Leeuw, S.; Dullaert, W. Factors Affecting Global Inventory Prepositioning Locations in Humanitarian Operations-A Delphi Study. J. Bus. Logist. 2016, 37, 59-74. [CrossRef]

3. United Nations Office for the Coordination of Humanitarian Affairs (UNOCHA). Global Humanitarian Overview; United Nations Office for the Coordination of Humanitarian Affairs: New York, NY, USA, 2019.

4. Apte, A. Humanitarian Logistics: A New Field of Research and Action, Foundations and Trends in Technology, Information and Operations Management; 3:1-100; Now Publishers: Boston, MA, USA, 2009.

5. CRED. The Human Cost of Natural Disasters-A Global Perspective; Centre for Research on the Epidemiology of Disasters: Brussels, Belgium, 2015.

6. Ryan, B.; Franklin, R.; Burkle, F.; Smith, E.; Aitken, P.; Watt, K.; Leggat, P. Ranking and prioritizing strategies for reducing mortality and morbidity from noncommunicable diseases post disaster: An Australian perspective. Int. J. Disaster Risk Reduct. 2017, 27, 223-238. [CrossRef]

7. Harvey, C. Scientists Can Now Blame Individual Natural Disasters on Climate Change; E\&E News Climate Wire: Washington, DC, USA, 2018.

8. Canyon, D.V.; Ryan, B.J.; Burkle, F.M. Military Provision of Humanitarian Assistance. J. Homel. Secur. Emerg. Manag. 2017, 14, 1-12. [CrossRef]

9. Spiegel, P. The humanitarian system is not just broke, but broken: Recommendations for future humanitarian action. Lancet 2017. [CrossRef]

10. Oloruntoba, R.; Gray, R. Humanitarian aid: An agile supply chain? Supply Chain Manag. 2006, 11, 115-120. [CrossRef]

11. Charles, A.; Lauras, M.; VanWassehove, L.; Dupont, L. Designing an efficient humanitarian supply network. J. Oper. Manag. 2016, 47, 58-70. [CrossRef]

12. Reith, L. E.C. and U.S. Approaches to Business Engagement in Humanitarian Action. 2009. Available online: http://www.disastergovernance.net/fileadmin/gppi/web_versions_Business_non_commercial_ response.pdf (accessed on 1 August 2018). 
13. UNOCHA. Guidelines on the Use of Military and Civil Defence Assets to Support United Nations Humanitarian Activities in Complex Emergencies; UNOCHA: New York, NY, USA, 2006.

14. UNOCHA. The Use of Foreign Military and Civil Defence Assets in Disaster Relief-Oslo Guidelines; UNOCHA: New York, NY, USA, 2007.

15. Inter-Agency Standing Committee (IASC). Civil-Military Guidelines Reference for Complex Emergencies; United Nations: New York, NY, USA, 2008.

16. Croxon, J. Combat Controllers Crucial to Haiti Earthquake Relief. Available online: https://www.afsoc.af.mil/ News/Article-Display/Article/162960/combat-controllers-crucial-to-haiti-earthquake-relief/ (accessed on 25 January 2010).

17. Shaheen, K. MSF Stops Sharing Syria Hospital Locations After 'Deliberate' Attacks. 2016. Available online: www.theguardian.com/world/2016/feb/18/msf-will-not-share-syria-gps-locations-afterdeliberateattacks (accessed on 3 July 2016).

18. Médecins Sans Frontières (MSF). MSF to Pull Out of World Humanitarian Summit; MSF: Geneva, Switzerland, 2016. Available online: www.msf.org/en/article/msf-pull-out-world-humanitarian-summit (accessed on 3 July 2016).

19. UNOCHA. What Are Humanitarian Principles; On Message; UNOCHA: New York, NY, USA, 2012.

20. Humanitarian Policy Group. Time to Let Go: Remaking Humanitarian Action for the Modern Era. Humanitarian Policy Group, Overseas Development Group, London. 2016. Available online: https://www.odi.org/hpg/ remake-aid (accessed on 3 July 2016).

21. Canyon, D.; Burkle, F. The 2016 World Humanitarian Summit Report Card: Both Failing Marks and Substantive Gains for an Increasingly Globalized Humanitarian Landscape. PLoS Curr. Disasters 2016. Available online: http://currents.plos.org/disasters/index.html\%3Fp=30828.html (accessed on 17 October 2018).

22. The Syria Campaign (TSC). Taking Sides: The United Nations Loss of Impartiality, Independence and Neutrality in Syria. TSC, The Voices Project, United Kingdom: 2016. Available online: http://takingsides.thesyriacampaign. org/ (accessed on 3 July 2016).

23. Menzies, G. Stop the Boats: Do the Ends Justify the Means? Econ. Pap. 2015, 34, 229-242. [CrossRef]

24. Bredillet, C.; Tywoniak, S.; Dwivedula, R. What is a good project manager? An Aristotelian perspective. Int. J. Proj. Manag. 2015, 33, 254-266. [CrossRef]

25. Nascimento, D. One step forward, two steps back? Humanitarian Challenges and Dilemmas in Crisis Settings. J. Humanit. Assist. 2015, 18, 10-13.

26. Shanks, L. Why Humanitarian Aid Became Professional: The Experience of MSF; J. Humanitarian Assistance, Relief Web; UNOCHA: New York, NY, USA, 2014. Available online: https://reliefweb.int/sites/reliefweb.int/ files/resources/Why\%20Humanitarian\%20Aid\%20Became\%20Professional_\%20the \%20experience \%20of\% 20MSF\%20_\%20The\%20Journal\%20of\%20Humanitarian\%20Assistance.pdf (accessed on 1 August 2018).

27. GAR. Global Assessment Report on Disaster Risk Reduction 2013; UNDRR: Geneva, Switzerland, 2013.

28. Rawls, C.; Turnquist, M. Pre-positioning of emergency supplies for disaster response. Transp. Res. Part B: Methodol. 2010, 44, 521-534. [CrossRef]

29. Klibi, W.; Ichoua, S.; Martel, A. Prepositioning emergency supplies to support disaster relief: A case study using stochastic programming. Inf. Syst. Oper. Res. 2018, 56, 50-81. [CrossRef]

30. World Food Programme (WFP). UNHRD Humanitarian Response Depot-2018 in Review; WFP: Rome, Italy, 2018; Available online: https://unhrd.org/yir/ (accessed on 1 August 2018).

31. UNHRD. Standard Operating Procedures-UNHRD Network. UNHRD, Las Palmas, Spain. 2018. Available online: https://unhrd.org/sites/default/files/UNHRD\%20Standard\%20Operating\%20Procedures_2018.pdf (accessed on 19 September 2018).

32. IFRC. The Effect of IFRC Regional Logistics Concept on the Efficiency of Relief Item Delivery for the Population Affected by the Yogyakarta Earthquake in 2006. Available online: https://www.ifrc.org/PageFiles/ 91193/YY\%20Case\%20Study\%20Summary.pdf (accessed on 1 August 2018).

33. IFRC. The IFRC Regional Logistics Concept_Efficiency of Relief Item Delivery for the Myanmar Population Affected by Cyclone Nargis. Available online: https://www.ifrc.org/PageFiles/91193/Myanmar\%20Case\% 20Study\%20v3.pdf (accessed on 19 September 2018).

34. Hechmann, R.; Bunde-Birouste, A. Drug Donations in Emergencies, the Sri Lankan Post-tsunami Experience. J. Humanit. Assist. 2007, 9, 26. 
35. VanTassle, G.; Cuthbert, R. Judging the Effectiveness of International Aid: Nepal; American Public University System: Charlestown, WV, USA, 2015.

36. NEFAB. Total Cost of Logistics: How to Reduce Your Total Cost of Logistics. NEFAB, Dallas Texas. 2017. Available online: https://www.nefab.com/en/insights/how-to-reduce-packaging-cost (accessed on 15 October 2018).

37. Christopher, M.; Towill, D. Supply chain migration from lean and functional to agile and customized. Supply Chain Manag. 2000, 5, 206-213.

38. AHA Centre. Preparedness and Response; AHA Centre: Jakarta, Indonesia, 2019. Available online: https: //ahacentre.org/preparedness-response/ (accessed on 20 October 2018).

39. Pohlman, L. War Games: The Story of Aid and War in Modern Times; Penguin Viking: London, UK, 2011.

40. Narang, N. Assisting Uncertainty: How Humanitarian Aid can Inadvertently Prolong Civil War. Int. Stud. Q. 2014, 1-12, 12. [CrossRef]

41. Asia Pacific Economic Cooperative (APEC). 2019. Available online: https://www.apec.org/About-Us/AboutAPEC (accessed on 07 January 2019).

42. DiOrio, D. Operation Unified Response: Haiti Earthquake. 2010. Available online: https://jfsc.ndu.edu/ Portals/72/Documents/JC2IOS/Additional_Reading/4A_Haiti_HADR_Case_Study_revNov10.pdf (accessed on 20 December 2018).

43. United Nations. Partnership Story: DHL Disaster Response Teams; United Nations: New York, NY, USA, 2019. Available online: https://business.un.org/en/documents/7522 (accessed on 20 December 2018).

44. De Annuntiis, V. Regional Consultative Group (RCG) on Humanitarian Civil-Military Coordination for Asia and the Pacific; Liaison X:27-29; Center for Excellence in Disaster Management and Humanitarian Assistance (CFE-DMHA): Honolulu, HI, USA, 2018.

45. Chandra, A.; Shaela, M.; Sellars, C. What Role Does the Private Sector Have in Supporting Disaster Recovery, and What Challenges Does It Face in Doing So? RAND Corporation: Santa Monica, CA, USA, 2016.

(C) 2019 by the authors. Licensee MDPI, Basel, Switzerland. This article is an open access article distributed under the terms and conditions of the Creative Commons Attribution (CC BY) license (http://creativecommons.org/licenses/by/4.0/). 